\title{
Active and Positive: The Connection between Active Aging and Positive Psychology
}

\author{
Yonghan Zhu \\ University College London, London, United Kingdom \\ Email: zhuyonghan1992@126.com
}

How to cite this paper: Zhu, Y.H. (2019) Active and Positive: The Connection between Active Aging and Positive Psychology. Open Journal of Social Sciences, 7, 147-156. https://doi.org/10.4236/jss.2019.72012

Received: January 22, 2019

Accepted: February 16, 2019

Published: February 19, 2019

Copyright $\odot 2019$ by author(s) and Scientific Research Publishing Inc. This work is licensed under the Creative Commons Attribution International License (CC BY 4.0).

http://creativecommons.org/licenses/by/4.0/

\section{cc) (i) Open Access}

\begin{abstract}
Aging problem has swept the globe over last decade. With the extension of aging trend worldwide, the mental problem of old group becomes a serious risk. In this background, a "positive trend" has raised in the field of psychological and aging studies. With the rising of the trend, the research angle on psychological and aging issues transferred from negative to positive. This generates a rising of two concepts: active aging and positive psychology. These notions provide a new perspective of research on aging problem. This article suggests an understanding on the concepts of active aging and positive psychology. Relying on the discussion of concepts, a theoretical analysis is employed to understand the connection between active aging and positive psychology. It finds that those core components of active aging, such as psychological health, social participation and social welfare, are key factors to improve the experience of positive psychology. Also, the level of positive psychology plays a key role in evaluating the outcome of active aging practice.
\end{abstract}

\section{Keywords}

Aging Problem, Active Aging, Positive Psychology, Subjective Well-Being

\section{Introduction}

In 1996, World Health Organization (WHO) presented the concept of active aging. Two years later, Seligman stated the concept of positive psychology in the conference of American Psychological Association (APA). These two concepts were introduced in a similar background. Before the appearance of active aging, the main perspective on aging was negative due to the worries on acute labour shortage and high social welfare expenditure [1]. Also, most of psychological research over the $20^{\text {th }}$ century focused on negative issues, such as psychosis, depression, anxiety and manic. In this background with full of negative atmos- 
phere, although the improvement in psychological and aging studies became obvious, human especially the olds, experienced increasing mental problems. This is opposite to the purpose of psychological research [2].

With the growth of economy and the development of technology, the old group enjoys rich resources and advanced outcomes than ever before. Hence, there are less mental problems and more happiness among the old group in theory, but the fact is precisely opposite. With the expansion of aging trend, the risk of mental and social problems becomes serious than ever before. Thus, a critical thinking should be inevitably undertaken in the methodology of psychological and aging research: should we only conduct research from a negative angle? As an answer to this question, active aging and positive psychology rise in the field of social science. These two concepts are based on the positive part of human nature. Thus, there is an inner connection between them. The connection could provide a possibility for the collaboration between active aging and positive psychology, and the collaboration has potential to develop a new methodology to cope with aging problem [3]. This article suggests an understanding on the connection between active aging and positive psychology. It is believed that this work could devote to the future studies on the collaboration between these two notions.

To achieve this purpose, a theoretical analysis is employed in this article to understand the connection between active aging and positive psychology. Firstly, it explores the development of active aging as a concept, and interprets active aging through three dimensions: health, participation and welfare. Then, it introduces the origin of positive psychology and explains one of the most important notions in this theory: subjective well-being. Based on these works, an analysis is conducted to understand the connection between the three dimensions of active aging and subjective well-being.

\section{Active Aging: A Dynamic Process through Lifespan}

\subsection{From Successful Aging to Active Aging}

Population aging refers to an increasing median age and a decreasing young age in the population. Generally, an aging society means people over 60 account for over $10 \%$ of total population or people over 65 make up over $7 \%$ of total population [4]. In order to cope with increasingly serious aging problem, many theories and policies has been presented over last 70 years. Successful aging, productive aging, healthy aging and active aging are the famous theories that cope with aging problem from positive angle. The concept of successful aging can be traced back to the 1950s, it refers to the process of developing and maintain the functional ability that enables well-being in old age [5]. Productive age was first presented by Robert in 1983, it means the participation of older people in various activities that devote to generate goods or services or develop the capacity to produce goods or service [6]. This notion mainly focuses on body health. In 1990, the World Health Organization stated a new notion which named healthy 
aging. This notion extends the scope of health to cover both body and mentality [7]. Table 1 displays the development from successful aging to health aging. In 1996, active aging was presented, it become a more comprehensive concept by refining the content of successful aging, productive aging and healthy aging. Health, participation and welfare are three key component of active aging.

\subsection{The Model of Active Aging}

Health means the old group maintains ability to keep health on body and mentality. Thus, they can constantly adapt to social change [8]. Participation means the old group joins the social development positively and promote the social development initiatively [9]. Welfare refers to the society is accountable to the old group for their wellbeing. To achieve their wellbeing, the society is supposed to construct a whole system which includes policy support, resource supply and monitor method [10] (Figure 1).

Activity aging revolutionizes the values on aging process. Over a long period, the old group has been considered as the burden of society because the more percentage of old people means the less population of labour force. However, activity aging transfers this negative perspective to positive view. In this theory, the old group is not burden but treasures, human society will benefit from their life experiences and wisdom. Those old people could use their own way to join and promote the social development, such as volunteering and reemployment [11].

Table 1. The expansion of objective from successful aging to healthy aging.

\begin{tabular}{ccc}
\hline Theory & Time & Objective \\
\hline Successful aging & $1950 \mathrm{~s}$ & Ability maintenance in old age \\
Productive aging & 1983 & Ability maintenance and social production \\
Healthy aging & 1990 & Maintenance on body and mentality in old age \\
\hline
\end{tabular}

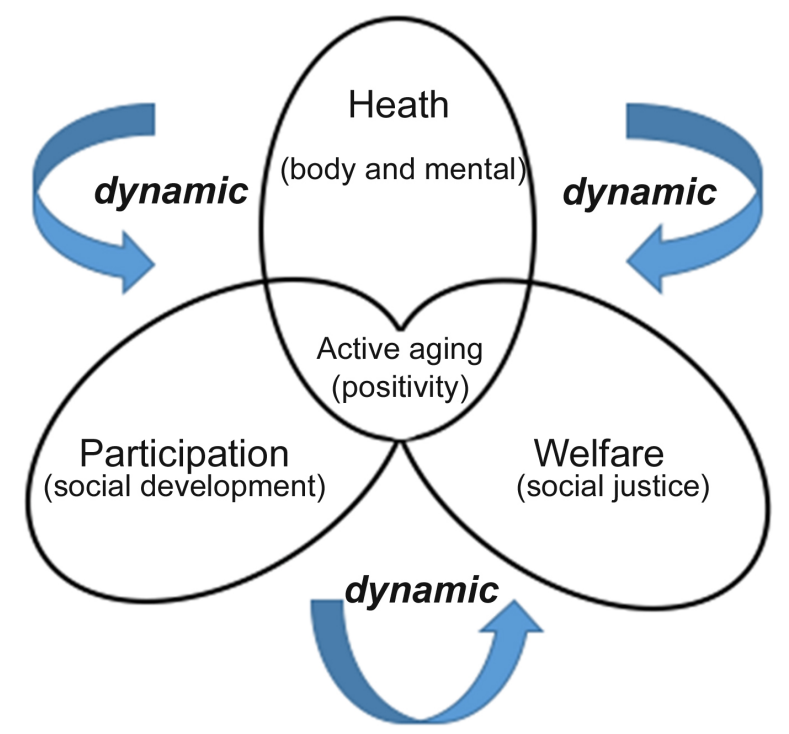

Figure 1. A model of active aging. 
Moreover, active aging is a dynamic process which accompanies with the whole lifespan of human being. It means people should prepare active aging at an early age. Hence, the maintenance of health, the building of participation interest and the development of social welfare system are supposed to be with people in their whole lives [12].

\section{Positive Psychology: Positive Perspective and Approach}

\subsection{Origin and Levels}

The embryo of positive psychology could be tracked back to Terman's discussion and Jung's study in the 1930s. In the 1960s Humanistic psychology generated the research on human potential, and this further promoted the development of positive psychology. However, due to the impact of World War II, the mainstream of psychological research transferred to pathological psychology and negative psychology. The main duty of psychology during that period was to heal the trauma of war [13].

In the end of the $20^{\text {th }}$ century, peace and development become the main topic worldwide. In this background, the main duty of psychology changed, more psychological research attempted to achieve social sustainability and provide a better life for human being. Thus, many new tasks, such as virtue cultivation, character strength and potential achievement were presented in psychological field.

Positive psychology raised in this background, the main purpose of this discipline is to understand and stimulate human virtue. It advocates exploring human nature from a positive angle and obtaining positive power through the process of exploration [14]. The value of "positivity" is emphasized in the theory of positive psychology because it believes those positive values in human being are able to cure mental illness and guide mankind to a better life [15].

Basically, positive psychology could be divided into three levels: individual level, group level and social level. At individual level, the research focuses on individual, it attempts to dig positive features in human nature, such as encourage, creativity, wisdom and tenacity [16]. Then, it refines power from positive features to cope with problems in daily life. At group level, the research focuses on organizations and institutions. It seeks to build a positive working environment through positive coach and positive therapy. At the social level, the research focuses on social system. The objective of it is to provide a positive social order for achievement of well-being, cultivation, justice, tolerance and sustainability [17]. Clearly, there is a progressive relation in three levels, and positivity is the main axle which links them. Figure 2 displays the specific contents at each level and the whole relation among them.

\subsection{Subjective Well-Being: Linking the Positive Psychology and Active Aging}

Subjective well-being (SWB) is one of most important notions in the theory of 


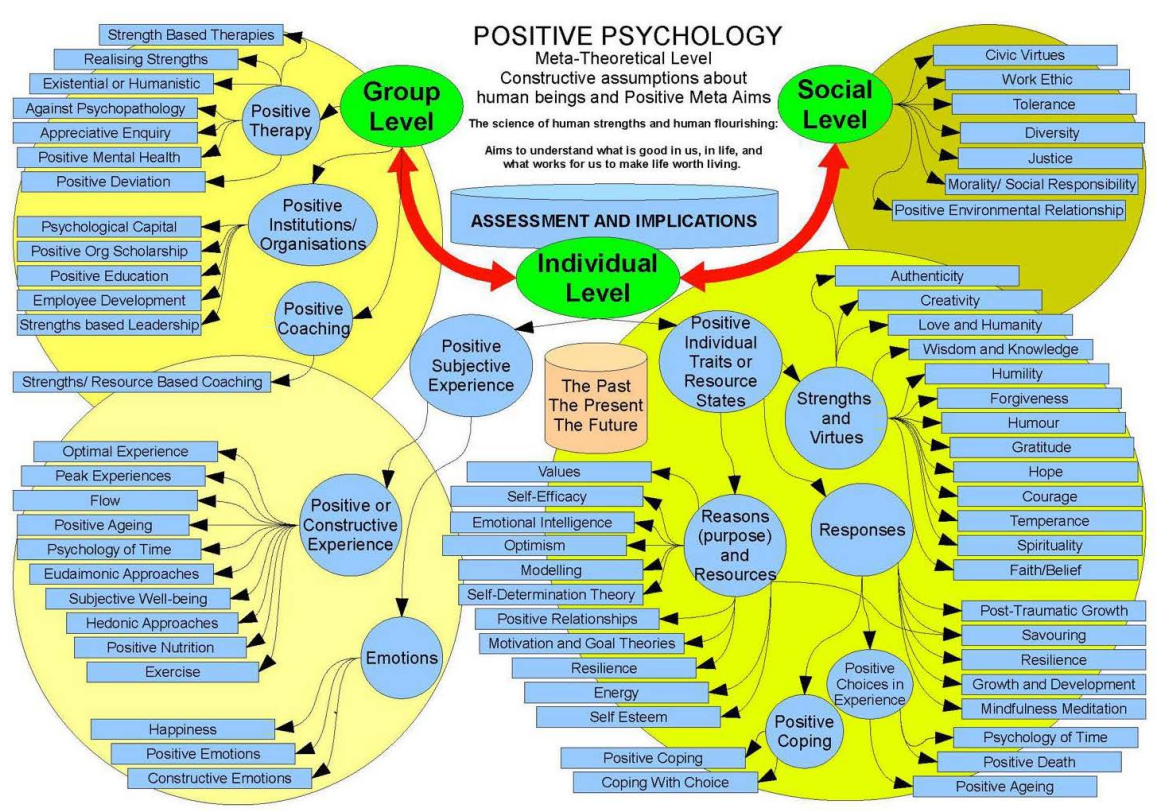

Figure 2. Three level of positive psychology [18].

positive psychology. It refers to a self-reported measure of life quality and life condition. In 1984, Diener developed a tripartite model of subjective well-being, the model pointed out three distinct but usually related components of wellbeing: frequent positive affect, infrequent negative affect and cognitive evaluation such as life satisfaction [19].

This measure is highly dependent on individuals and it covers most of factors of well-being, including both body and mental condition. Due to the comprehension of subjective well-being, it becomes a significant standard of active aging. Thus, as an indispensable component of positive psychology, subjective well-being bridges positive psychology and active aging.

\section{The Connection between Active Aging and Positive Psychology}

Basically, health, participation and welfare constitute the core of active aging, the relation between active aging and positive psychology is firstly reflected by the connection between the three factors and subjective well-being. Health, participation and welfare are the important power to achieve subjective well-being. Furthermore, positive psychology could stimulate positive motion among the old group and give them motivation to participate social activities and sustain health. Namely, positive psychology could help to promote the implement of active acting.

\subsection{Health Is the Basic to Achieve Subjective Well-Being}

According to the World Health Organization, health means a well condition in both body and mentality [20]. Due to the deterioration of human physiology and the impact of negative pressures in daily life, many old people have physical 
and/or mental problems. With the increase of old population, the number of people who have physical problems and/or mental illness also rises. This causes a serious challenge to subjective well-being in the whole society.

Normally, the deterioration of human physiology and mentality has negative impact on daily life and social participation of old people. In some cases, the physical or mental problems not only cause high pressures on old people, but also on their families. Hence, with the deterioration of health, the olds usually bear huge psychological burden, and the burden further challenges their mental health. Through this process, the life satisfaction of old people is declined.

Thus, health could be considered as the basic to achieve subjective well-being. Unhealthy condition will cause burden and pain, and further decrease subjective well-being of old group. On the contrary, healthy condition will guarantee the body without pain and the ability to regular social activities, the subjective well-being could benefit from these factors.

\subsection{Participation Has Positive Impact on Subjective Well-Being}

Among all the factors which affect subjective well-being, social participation enjoys a significant status. It greatly devotes to increasing the healthy level and satisfaction of the elderly.

A survey in China proved the important role of social participation in subjective well-being. In 2012, Wang conducted a research to understand the impact of social participation on mental condition of the elderly, he investigated 100 old people in several communities and the pointed out $79.2 \%$ interviewees agreed the positive role of social participation in their daily life [21].

Indeed, according to Social-role Theory, everyone acts a social role. The social relation from one to another is based on the interaction between different roles [22]. However, many acting work stop after retire. Thus, social participation could help old people continue their action in retired life. This offers the elderly a sense of belonging and a sense of being capable. Through this process, old people are able to sustain their social values and realize their existing meaning, the subjective well-being benefits from these positive feelings. Also, Active Theory supports the positive connection between participation and subjective well-being. According to Active Theory, old group still keep their psychological link with society after they retires. The disappearance of this link could cause many mental problems that decline the satisfaction of old people, such as autism, aphasia and amnesia. However, participation helps to sustain this psychological link. Thereby, participation plays a positive role in improving subjective well-being.

\subsection{Welfare Is Significant Step to Improve Subjective Well-Being}

Welfare also has positive effect on subjective well being. To understand the link between the rank of subjective well-being and the level of welfare among different countries, this research employs World Database of Happiness (WDH) and Forbes Ranking of Happiness to conduct a data analysis, Table 2 displays the outcome of finding. 
Table 2. Ranking of World Database of Happiness in 2017 [23].

\begin{tabular}{|c|c|c|c|}
\hline Ranking & Country & Score & Model \\
\hline 1 & Costa Rica & 8.50 & \\
\hline 2 & Denmark & 8.34 & Welfare State \\
\hline 3 & Puerto Rico & 8.32 & \\
\hline 4 & Iceland & 8.15 & Welfare State \\
\hline 5 & Switzerland & 7.99 & Welfare State \\
\hline 6 & Canada & 7.97 & Welfare State \\
\hline 7 & Finland & 7.90 & Welfare State \\
\hline 9 & Norway & 7.82 & Welfare State \\
\hline 10 & Sweden & 7.80 & Welfare State \\
\hline 12 & Australia & 7.77 & Social Security \\
\hline 22 & America & 7.44 & Social Security \\
\hline 24 & Span & 7.30 & Social Security \\
\hline 28 & Great Britain & 7.20 & Welfare State \\
\hline 34 & Germany & 6.98 & Social Security \\
\hline 36 & Singapore & 6.88 & Individual Saving \\
\hline 39 & Italy & 6.78 & Social Security \\
\hline 47 & France & 6.58 & Social Security \\
\hline 58 & China & 6.27 & \\
\hline 62 & Japan & 6.17 & Social Security \\
\hline
\end{tabular}

According to the World Database of Happiness in 2017, most of countries from rank 1 to 10 were Welfare State. The Forbes Ranking of Happiness in 2015 also provided the same evidence.

Clearly, the top 4 countries in Table 3 are Welfare State. Over 68\% people enjoyed happiness and the average satisfaction level is between 7.8 - 7.9. According to these two tables, welfare positively affects subjective well-being. Thus, welfare could be considered as a significant step to achieve a high level of subjective well-being, an advanced welfare system is beneficial to subjective well-being.

\section{Conclusions}

Active aging and positive psychology emphasize the positivity in human nature. These two theories transfer the research angle for aging problem. With the impact of active aging and positive psychology, more research focuses on human being through a positive perspective, and the meaning of positivity creates a new purpose of aging study: to believe the positive power in human nature and lead society to happiness.

Basically, there is a connection between active aging and positive psychology. The main components of active aging, health, participation and welfare, play important role in improving the key concept of positive psychology: subjective 
Table 3. The Forbes Ranking of Happiness in 2015 (\%) [24].

\begin{tabular}{|c|c|c|c|c|c|c|}
\hline Ranking & Country & The happiness & The poor & The suffering & Satisfaction Level & Model \\
\hline 1 & Denmark & 82 & 17 & 1 & 7.9 & Welfare State \\
\hline 2 & Fenland & 75 & 23 & 2 & 7.8 & Welfare State \\
\hline 3 & Norway & 69 & 31 & 0 & 7.9 & Welfare State \\
\hline 4 & Dutch & 68 & 32 & 1 & 7.7 & Welfare State \\
\hline 4 & Sweden & 68 & 30 & 2 & 7.9 & Welfare State \\
\hline 14 & America & 57 & 40 & 3 & 7.3 & Social Security \\
\hline 33 & Germany & 43 & 50 & 7 & 7.4 & Social Security \\
\hline 40 & Italy & 39 & 54 & 7 & 7.1 & Social Security \\
\hline 43 & Span & 36 & 58 & 6 & 7.0 & Social Security \\
\hline 81 & Singapore & 19 & 75 & 6 & 6.9 & Individual Saving \\
\hline 81 & Japan & 19 & 69 & 12 & 7.4 & Social Security \\
\hline 125 & China & 9 & 77 & 4 & 7.6 & \\
\hline
\end{tabular}

well-being. More specifically, health is the basic to achieve subjective well-being. Participation has positive impact on subjective well-being and welfare is significant step to improve subjective well-being. Furthermore, positive psychology could help to promote the implement of active acting. In the future studies on aging problem, there will be a further collaboration between active aging and positive psychology, such as how to employ the theory of positive psychology to stimulate the goodness of human nature and achieve the dynamic process of active aging in the whole lifespan. This could help government to promote social participation and reduce mental risk of old group. Thus, the understanding of the connection between these two theories in this research could devote to the future research on aging problem.

\section{Conflicts of Interest}

The author declares no conflicts of interest regarding the publication of this paper.

\section{References}

[1] Wu, C.P. (2013) The Interpretation of Active Aging. Aging Problem Research, 1, 4-13. http://www.cnki.com.cn/Article/CJFDTotal-LLKX201301003.htm

[2] Gao, J. (2005) The Subjective Well-Being of Old Group: A Literature Review. Social Psychology, 3, 19-22. http://www.cnki.com.cn/Article/CJFDTotal-SHXL200502006.htm

[3] Yang, C. (2009) Rethinking the Implement of Active Aging in Jiang Su Provence. Journal of Population, 3, 60-65. http://www.cnki.com.cn/Article/CJFDTotal-RKXK200903011.htm

[4] Chucks, J. (2010) Population Aging in Ghana: Research Gaps and the Way Forward. Journal of Aging Research, 1-8. https://doi.org/10.4061/2010/672157 
[5] Rowe, J.W. and Kahn, R.L. (1997) Successful Aging. Gerontologist, 37, 433-440. https://doi.org/10.1093/geront/37.4.433

[6] Schulte, P.A., Grosch, J., Scholl, J.C. and Tamers, S.L. (2018) Framework for Considering Productive Aging. Journal of Occupational and Environmental Medicine, 5, 60-65. https://doi.org/10.1097/JOM.0000000000001295

[7] Guralnik, J.M. and Kaplan, G.A. (1989) Predictors of Healthy Aging: Prospective Evidence from the Alameda County Study. American Journal of Public Health, 4, 501-518. https://doi.org/10.2105/AJPH.79.6.703

[8] Tokushige, A., Araki, D., Suzuki, M., Iwashaki, Y. and Ozawa, M. (2014) The Direction of Research on Active Aging and Healthy Life Expectancy in Japan. Open Journal of Nursing, 4, 475-482. https://doi.org/10.4236/ojn.2014.47050

[9] Paul, C., Ribeiro, O. and Teixeira, L. (2012) Active Ageing: An Empirical Approach to the WHO Model. Current Gerontology and Ceriatrics Research, 2012, 54-63. https://doi.org/10.1155/2012/382972

[10] Cornejo, R., Weibel, N., Tentori, M. and Favela, J. (2015) Promoting Active Aging with a Paper-Based SNS Application. The Conference of Pervasive Computing Technologies for Healthcares, 3 August 2015, 209-212. https://doi.org/10.4108/icst.pervasivehealth.2015.259069

[11] Zasimova, L. and Shelunicova, M. (2014) Measuring Active Aging for Government Policy Planning: A Case of Russia. Higher School of Economics Research, 1-30. https://doi.org/10.2139/ssrn.2385832

[12] Walker, A. and Zaidi, A. (2016) New Evidence on Active Aging in Europe. Leibniz Information Centre for Economics, 139-144. https://doi.org/10.1007/s10272-016-0592-0

[13] Li, J.Z., Wang, W.Z. and Shi, J.N. (2003) Positive Psychology: A New Research Angle. The Development of Psychology, 3, 321-327. http://www.cnki.com.cn/Article/CJFDTotal-XLXD200303013.htm

[14] Miller, A. (2008) A Critique of Positive Psychology or "The New Science of Happiness". Journal of Philosophy of Education, 3, 591-608. https://doi.org/10.1111/j.1467-9752.2008.00646.x

[15] Cui, L.J. and Zhang, G.C. (2005) A New Approach of Psychology: Literature Review on Positive Psychology. Chinese Psychology, 2, 402-405. http://www.cnki.com.cn/article/cjfd2005-xlkx200502034.htm

[16] Cao, M.X. and Liu, X.P. (2008) From Learning Positivity to Positive Psychology: The Seligman's Work on the Development of Psychology. The Development of Psychology, 4, 562-566. http://www.cnki.com.cn/Article/CJFDTotal-XLXD200804010.htm

[17] Shoshani, A. and Steinmetz, S. (2014) Positive Psychology at School: A School-Based Intervention to Promote Adolescents' Mental Health and Well-Being. Journal of Happiness Studies, 15, 1289-1311. https://econpapers.repec.org/RePEc:spr:jhappi:v:15:y:2014:i:6:p:1289-1311

[18] Seligman, M.E. and Csikszentmihalyi, M. (2000) Positive Psychology: An Introduction. American Psychologist, 55, 5-14. https://doi.org/10.1007/978-3-319-38779-6_3

[19] Diener, E., Suh, E.M., Lucas, R.E. and Smith, H.L. (1999) Subjective Weil-Being: Three Decades of Progress. Psychological Bulletin, 125, 276-302. https://psycnet.apa.org/doi/10.1037/0033-2909.125.2.276

[20] WHO (2001) Health and Aging: A Discussion paper. World Health Organization, 1-36. http://www.who.int/iris/handle/10665/66682 
[21] Wang, P. (2012) The Research on Old People's Participation in Urban Area. The Development of Psychology, 3, 35-49.

http://cdmd.cnki.com.cn/Article/CDMD-10533-1012477617.htm

[22] Serlin, I. (2011) The History and Future of Humanistic Psychology. Journal of Humanistic Psychology, 51, 428-431. https://doi.org/10.1177/0022167811412600

[23] Veenhoven, R., World Database of Happiness. Erasmus University Rotterdam, The Netherlands. http://worlddatabaseofhappiness.eur.nl

[24] The Forbes Ranking of Happiness in 2017.

http://www.cnki.com.cn/Article/CJFDTotal-CSXS201208012.htm 